\title{
Electrocatalytic Hydrogen Production Properties of Poly(3- aminobenzoic acid) doped with Metal Organic Frameworks
}

\author{
Kabelo E. Ramohlola ${ }^{1}$, Milua Masikini ${ }^{2}$, Siyabonga B. Mdluli ${ }^{2}$, Gobeng R. Monama ${ }^{1}$, \\ Mpitloane J. Hato ${ }^{1}$, Kerileng M. Molapo ${ }^{2}$,Emmanuel I. Iwuoha ${ }^{2}$, Kwena D. Modibane ${ }^{1, *}$ \\ ${ }^{1}$ Department of Chemistry, School of Physical and Mineral Science, University of Limpopo, \\ Polokwane, Sovenga 0727 South Africa \\ ${ }^{2}$ SensorLab, Chemistry Department, University of the Western Cape, Cape Town, South Africa \\ *E-mail: kwena.modibane@ul.ac.za
}

doi: $10.20964 / 2017.05 .58$

Received: 30 November 2016 / Accepted: 14 February 2017 / Published: 12 April 2017

\begin{abstract}
The design and development of inexpensive highly efficient electrocatalysts based on polymer organometallic composites for hydrogen production, underpins several emerging clean-energy technologies. In this work, for the first time, Poly(3-aminobenzoic acid) based metal organic framework (PABA/MOF) composite was synthesized by chemical oxidation of 3-aminobenzoic acid monomer in the presence of metal organic framework (MOF) content. Poly(3-amino benzoic acid) (PABA), MOF and PABA/MOF composite were characterized by ultraviolet visible (UV-vis) and fourier transform infrared (FTIR) spectroscopy, powder X-ray diffraction (XRD), thermal gravimetric analysis (TGA), scanning electron microscope (SEM), transmission electron microscope (TEM), energy dispersive X-ray spectroscopy (EDS, EDX), selected area electron diffraction (SAED) and cyclic voltammetry $(\mathrm{CV})$. Detailed structural and morphological characterizations established that PABA is wrapping MOF. Furthermore, spectroscopic analyses provided information that MOF was incorporated on the backbone of PABA as indicative of an easier path for the electron transport and plentiful active sites for the catalysis of hydrogen evolution reaction (HER) in acidic electrolyte. Experiments probing the electrochemical properties revealed that the composite was very stable and robust and had exceptionally properties. Significant HER was generated by the composite in dimethyl sulfoxide/tetrabutylammonium perchlorate (DMSO/TBAP) supporting electrolyte in the presence of hydrogen source by applying a potential to the electrode.
\end{abstract}

Keywords: poly(3-aminobenzoic acid), metal organic frameworks, electrochemistry, hydrogen evolution reaction, Tafel plot.

\section{FULL TEXT}


(C) 2017 The Authors. Published by ESG (www.electrochemsci.org). This article is an open access article distributed under the terms and conditions of the Creative Commons Attribution license (http://creativecommons.org/licenses/by/4.0/). 